\title{
Metabolic control of epithelial-immune interactions in the skin
}

Xiaolei Ding ${ }^{1}$, Sebastian Willenborg ${ }^{1}$, Parisa Kakanj², Maria Leptin²,3,4 and Sabine A. Eming ${ }^{1,3,4}$

1Dermatology: 2 Institute for Genetics; ${ }^{3}$ Center for Molecular Medicine Cologne;

${ }^{4}$ Cologne Cluster of Excellence for Aging Research, University of Cologne, Germany

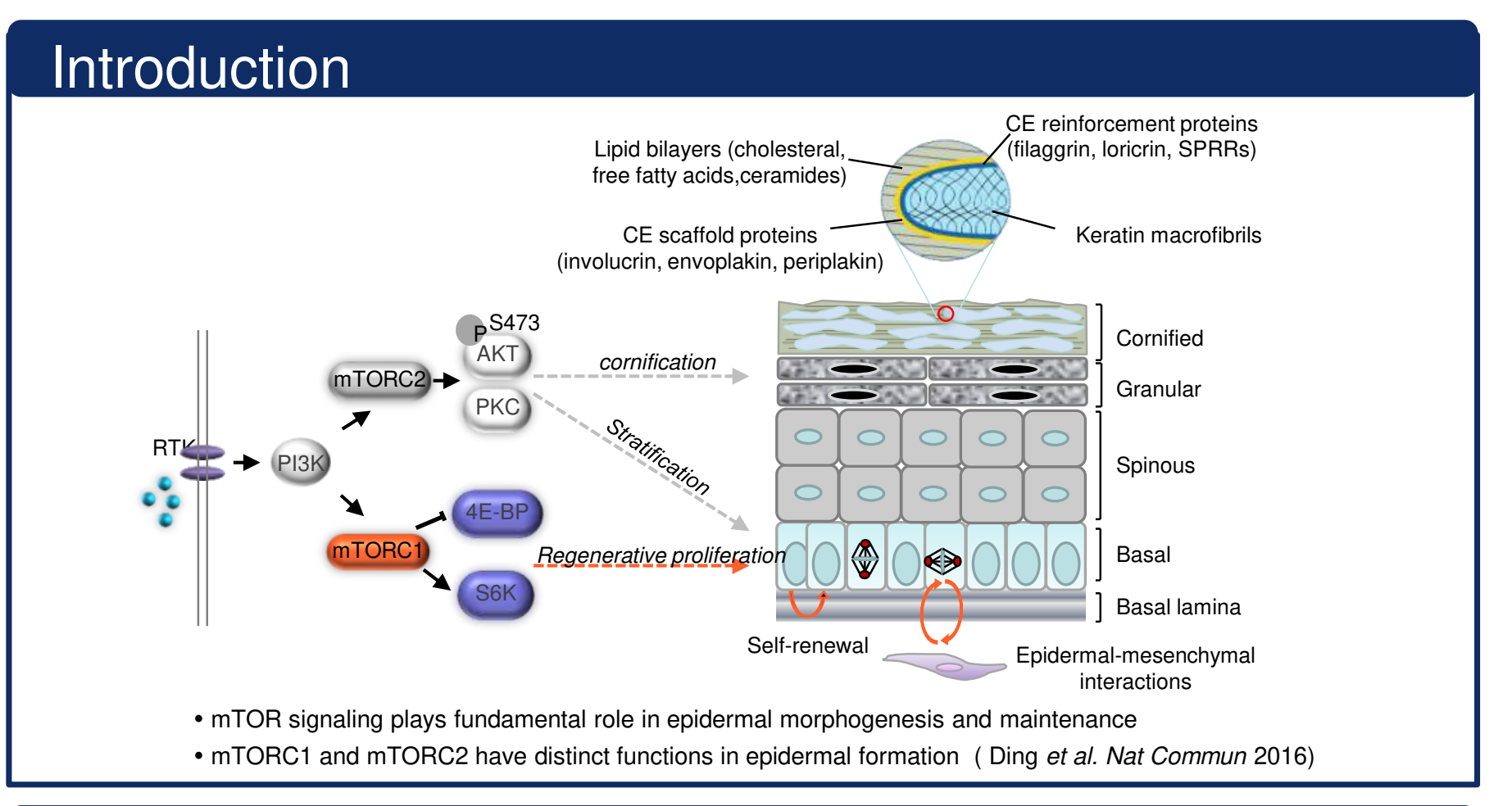

Results

- RicEKO newborns display an ichthyosis-like phenotype
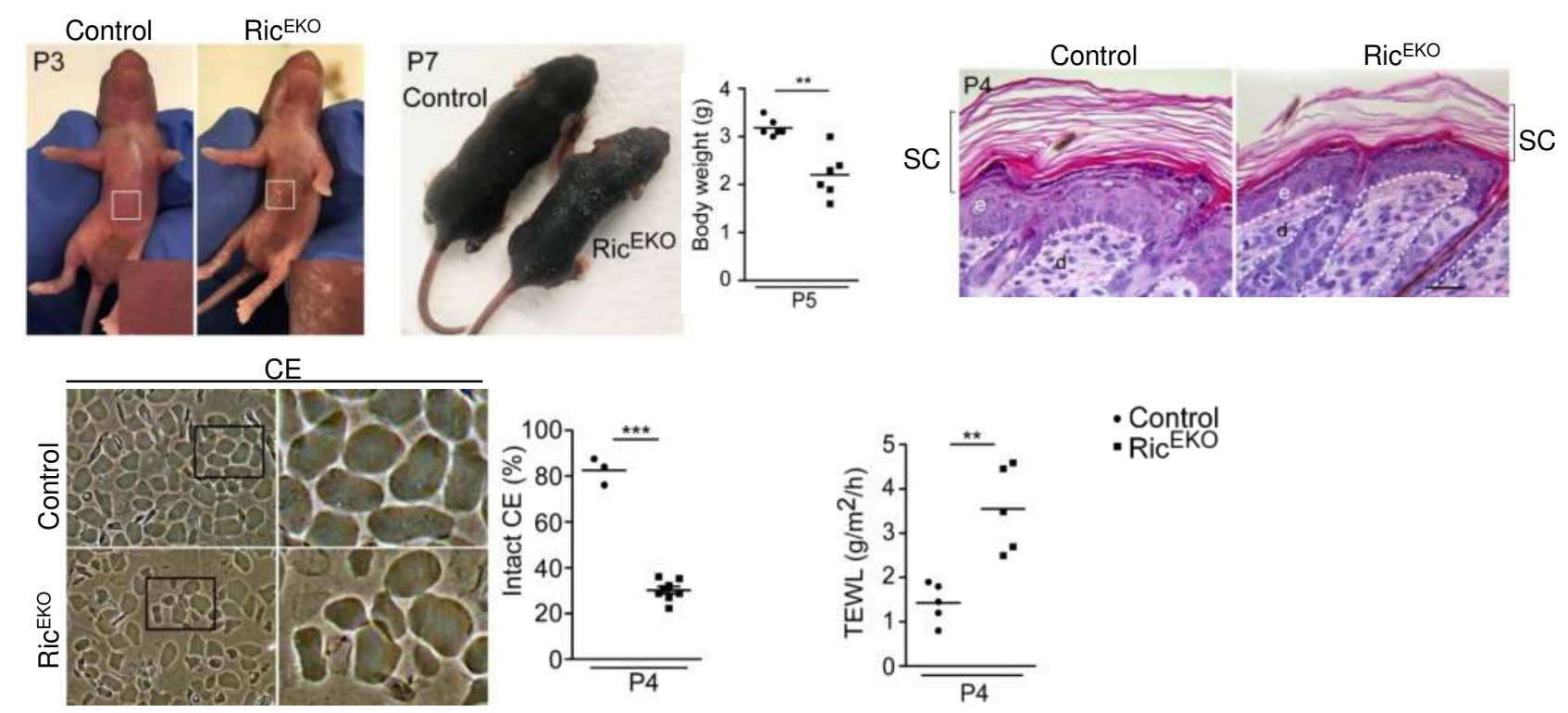

- mTORC2 deficiency induces a compensatory transcriptional epidermal repair program in $\mathrm{Ric}^{\mathrm{EKO}}$ mice
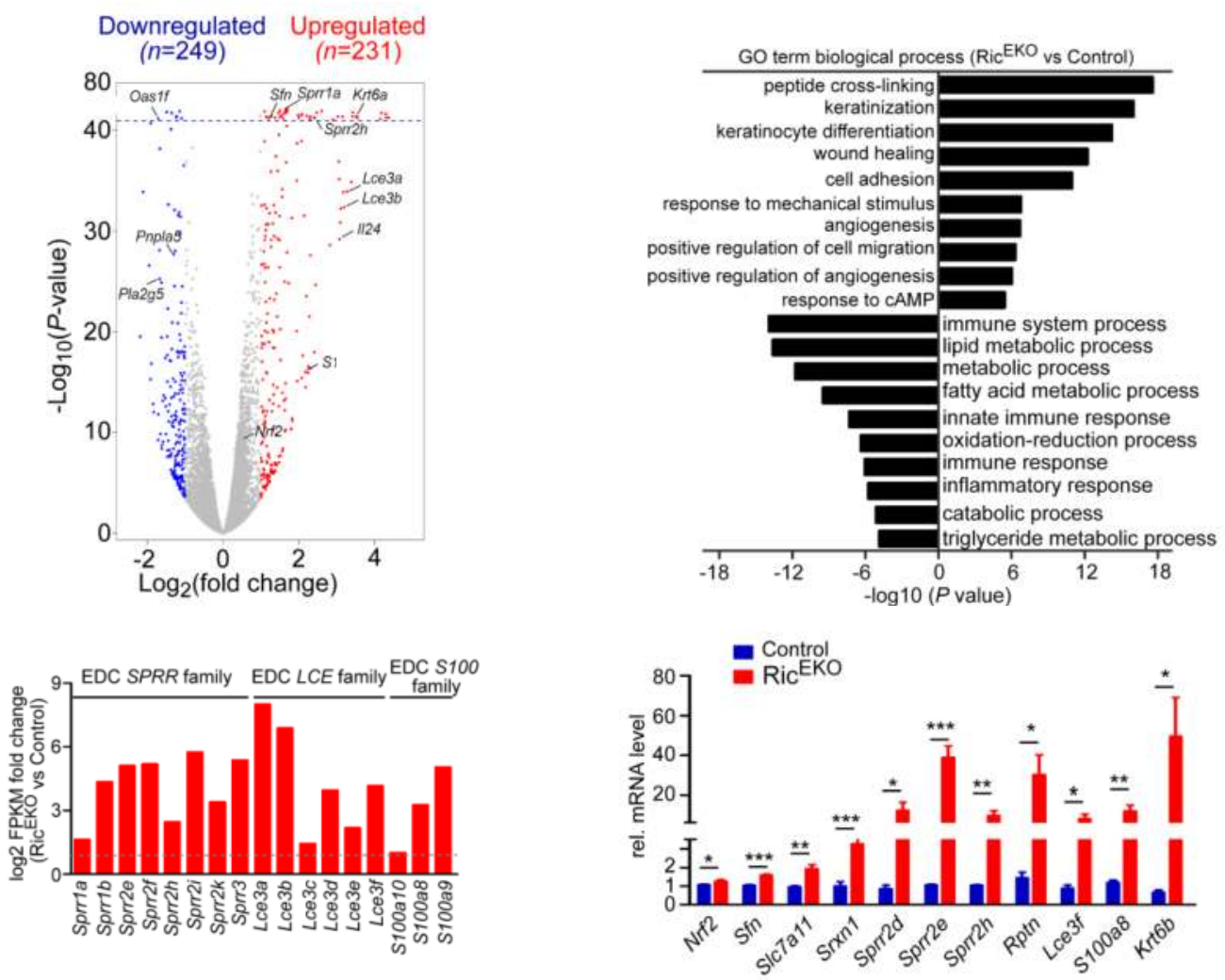

- mTORC2 controls epidermal lipid metabolism

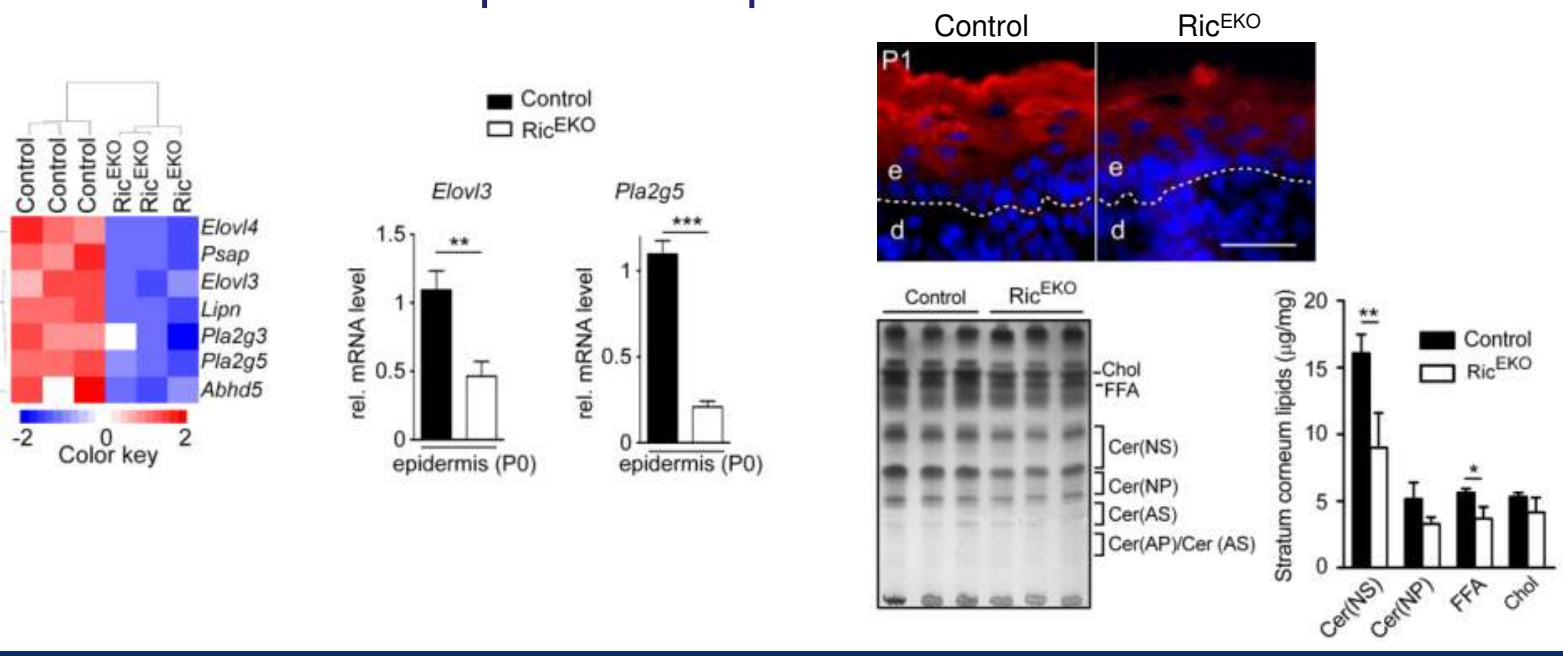

- Impaired profilaggrin processing in Ric ${ }^{\mathrm{EKO}}$ epidermis

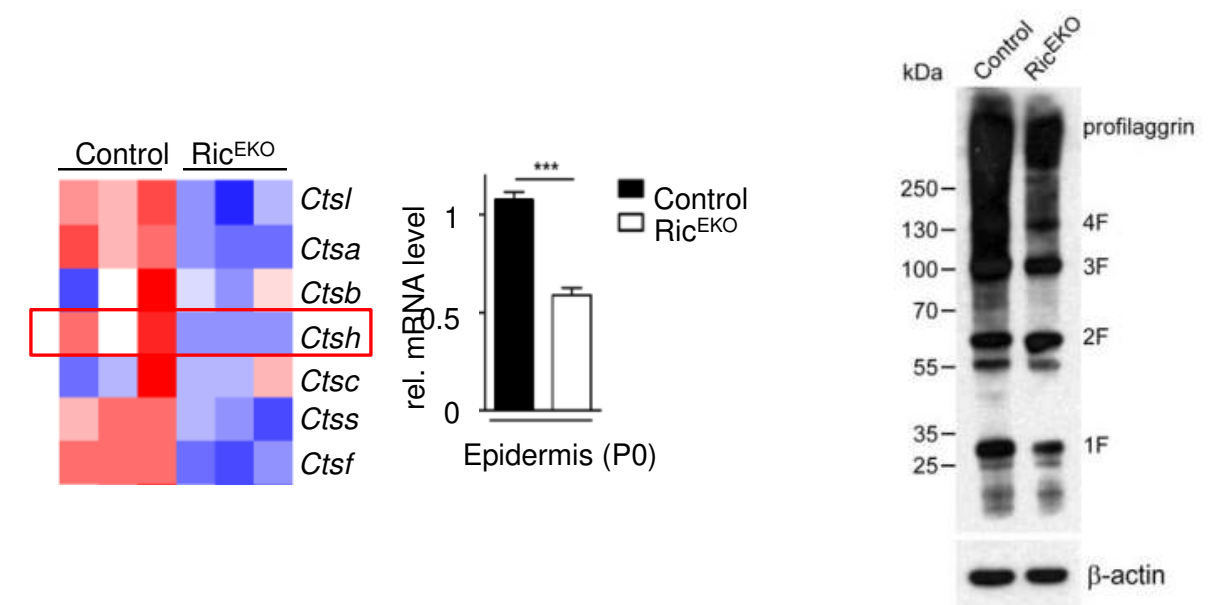

- mTORC2-Akt signaling pathway controls profilaggrin processing

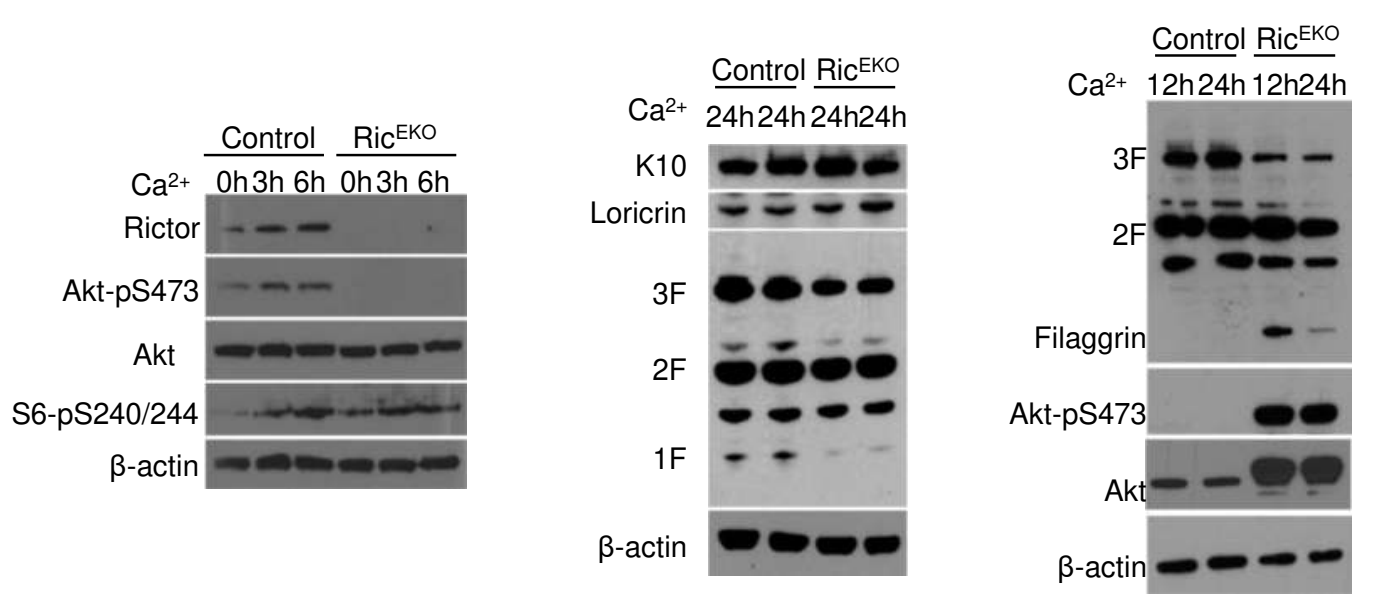

- Epidermal mTORC2 determines immune cell composition in the skin
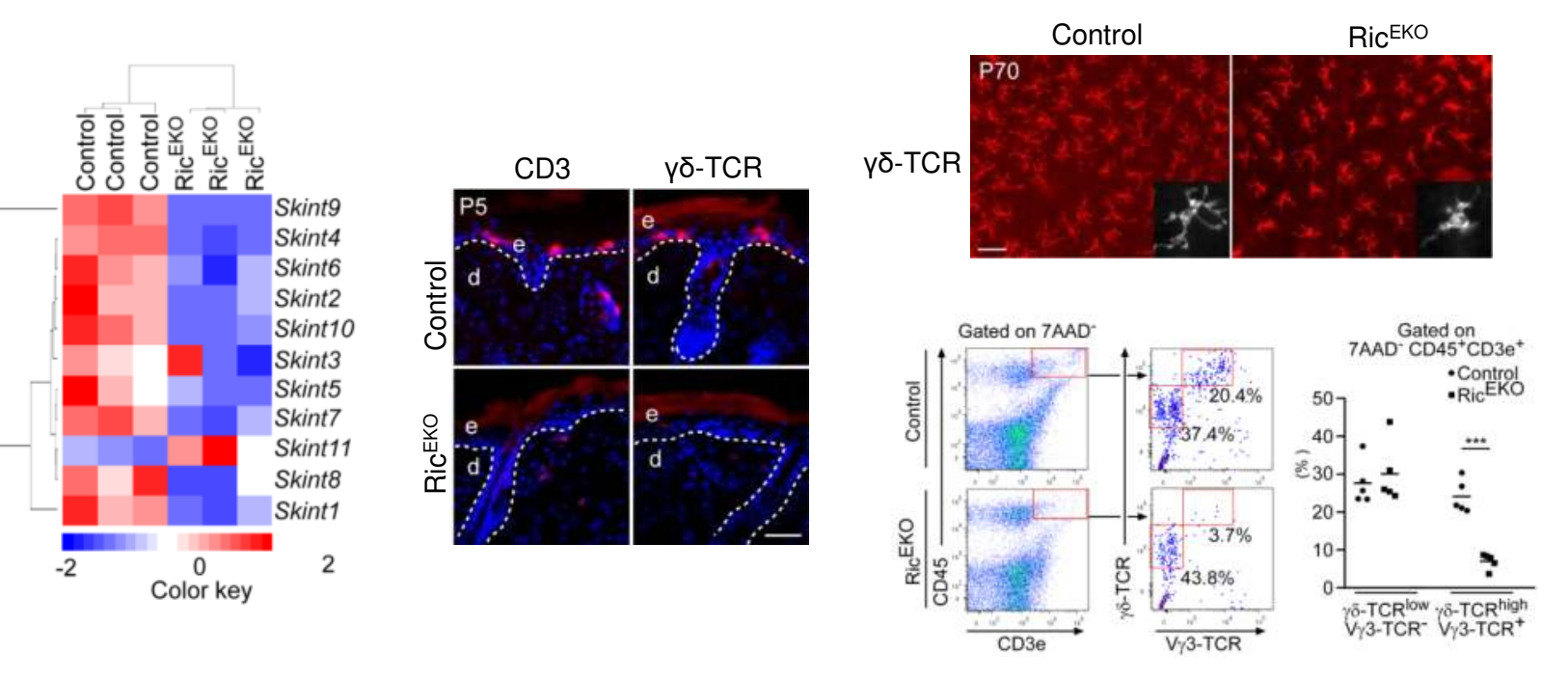

- Ric EKO mice display enhanced percutaneous immune responses
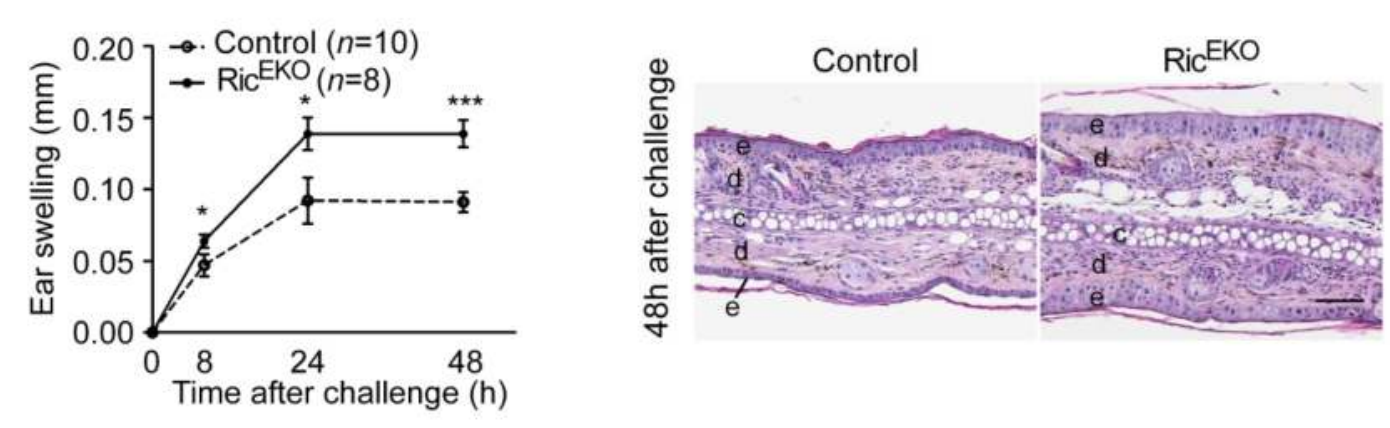

Conclusions

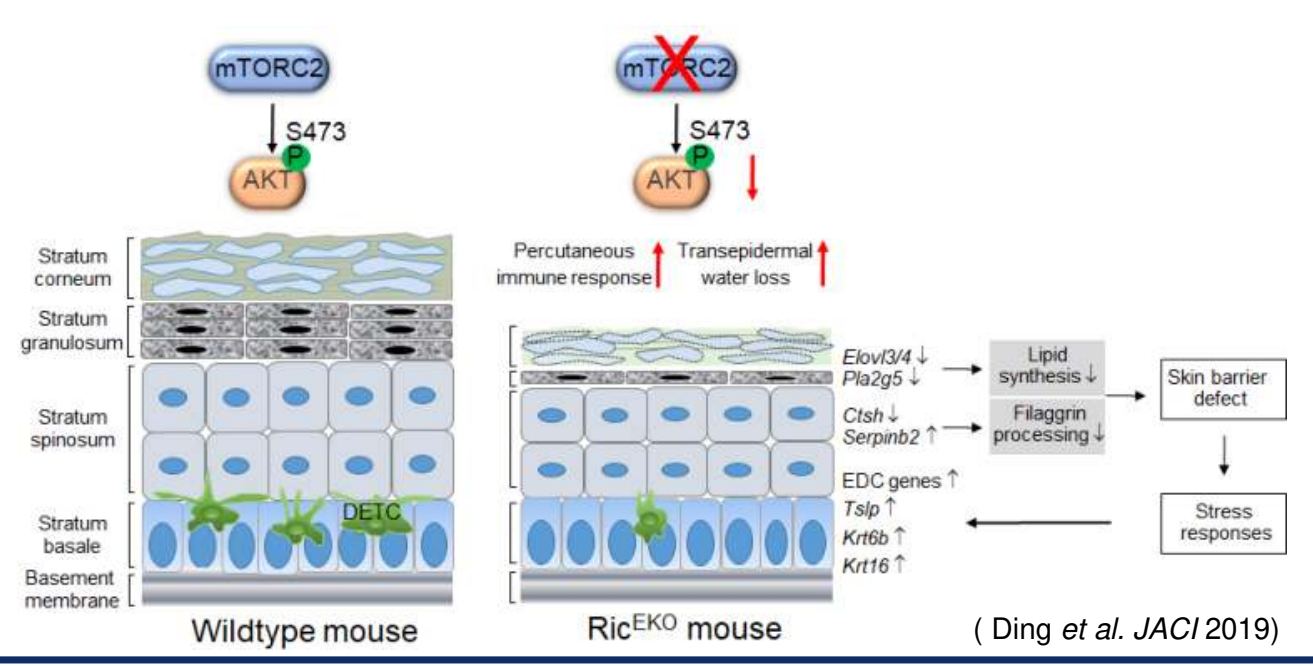

